\title{
Using Collaborative Agent-Based Computer Modeling to Explore Tri-Trophic Cascades with Elementary School Science Students
}

\author{
Anthony J. Petrosino', Max K. Sherard', Jason R. Harron', Walter Stroup ${ }^{2}$ \\ ${ }^{1}$ Department of Curriculum and Instruction, University of Texas at Austin, Austin, USA \\ ${ }^{2}$ University of Massachusetts-Dartmouth, Dartmouth, USA \\ Email: ajpetrosino@austin.utexas.edu
}

How to cite this paper: Petrosino, A. J., Sherard, M. K., Harron, J. R., \& Stroup, W. (2018). Using Collaborative Agent-Based Computer Modeling to Explore Tri-Trophic Cascades with Elementary School Science Students. Creative Education, 9, 615-624. https://doi.org/10.4236/ce.2018.94043

Received: February 27, 2018

Accepted: April 15, 2018

Published: April 18, 2018

Copyright $\odot 2018$ by authors and Scientific Research Publishing Inc. This work is licensed under the Creative Commons Attribution International License (CC BY 4.0).

http://creativecommons.org/licenses/by/4.0/

\begin{abstract}
This paper investigates an in-service teacher and her student's abilities to utilize, implement, and enact a participatory agent-based modeling program, developed as part of the group-based cloud computing (GbCC) for STEM Education Project funded by the National Science Foundation. In this first cycle of design-based implementation research with an in-service teacher and her 300 students, we examine student participatory learning and teacher experience. By implementing models with teachers, we intend to 1) improve iteratively the GbCC learning technologies and 2) develop more informed and aligned pedagogies for teaching in socially mediated and generative learning environments.
\end{abstract}

\section{Keywords}

Group-Based Cloud Computing, NetLogo, In-Service, Modeling

\section{Introduction}

The most conspicuous feature of school-based learning is that it occurs in group settings; however, instruction typically engages only the individual by following the initiation-response-feedback sequence (Wells, 1993). For classrooms to engage in more socially mediated and generative teaching and learning, instructors must design situations for groups of students to construct relations between stored knowledge, experience, and new information (Wittrock, 1991). Using the taxonomy of generative design provided by Stroup, Ares, \& Hurford (2004), scientific modeling allows learners to engage in generative learning with the help of agent-based models deployed using the group-based cloud computing 
(GbCC) web-based platform (Petrosino \& Stroup, 2017; Stroup, Ares, Lesh, \& Hurford, 2007).

By merging NetLogo Web (Wilensky, 1997) with other open science and mathematic libraries within a highly interactive, browser-based, cloud-supported architecture, GbCC significantly extends the capabilities of the HubNet system (Wilensky \& Stroup, 2002) for implementing group-based participatory simulations. The result is an environment that allows learners to work collaboratively to participate in, author, and then share simulations and models of a wide array of phenomena. The GbCC architecture can be used to develop new environments and activities or resituate existing models or participatory simulations. The capabilities support learning across a range of domain content including disease transmission, population dynamics, physical phenomena, and social stratification. This study illustrates resituating and updating of the Wolves-Sheep Predation model (Wilensky, 1997; Wilensky \& Reisman, 2006), shown in Figure 1.

Rather than function as an individual-user simulation, we could use the GbCC architecture to create a network-mediated, group-based modeling activity ( $\mathrm{Pe}$ trosino \& Stroup, 2017), the Yellowstone Problem, for exploring a specific kind of complex food web-tri-trophic cascades-where the presence of predators and producers exerts significant control over population dynamics. We use the model to explore the consequences of the extirpation of wolves in Yellowstone National Park and the resulting ecological effects related to the power of top-down ecosystem control in tri-trophic cascades (Ripple \& Beschta, 2012). To introduce the activity, a short video produced by Sustainable Human (How Wolves Change Rivers, 2014) was used to illustrate how the reintroduction of wolves in Yellowstone had a number of impacts on the environment, including changing the flow of rivers. This scenario is more complicated than typical science curricula can model with representations like symbolic food webs. The complexity involved in how wolves shape rivers-what we called the Yellowstone Problem-can be modeled using collaborative agent-based models. A concept map was developed to illustrate some of the agents involved in this tri-trophic cascade (Figure 2).

The GbCC platform is a powerful computational tool; however, "powerful technological tools, in the absence of powerful pedagogy, detract from rather than contribute to learning" (Philip \& Garcia, 2013: p. 313). With this insight in mind, the goal of this paper is to 1) examine how the integrated GbCC environment informs the learning of ecology concepts and modeling knowledge through socially mediated forms of classroom activity and 2) determine changes to the model or activity design for future implementation.

\section{Methods}

Consistent with the goals of characterizing student participation while building in-service teacher capacity for pursuing more fully socially mediated approaches 


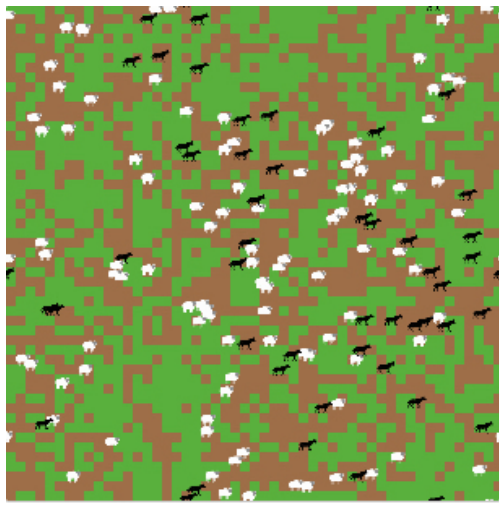

Figure 1. NetLogo wolf-sheep predation model. From netlogo wolf sheep predation model, by Wilensky, 1997, evanston, il: northwestern university, center for connected learning and computer-based modeling. used via a creative commons license. this model was used in the 4-day unit to teach students about the yellowstone problem.

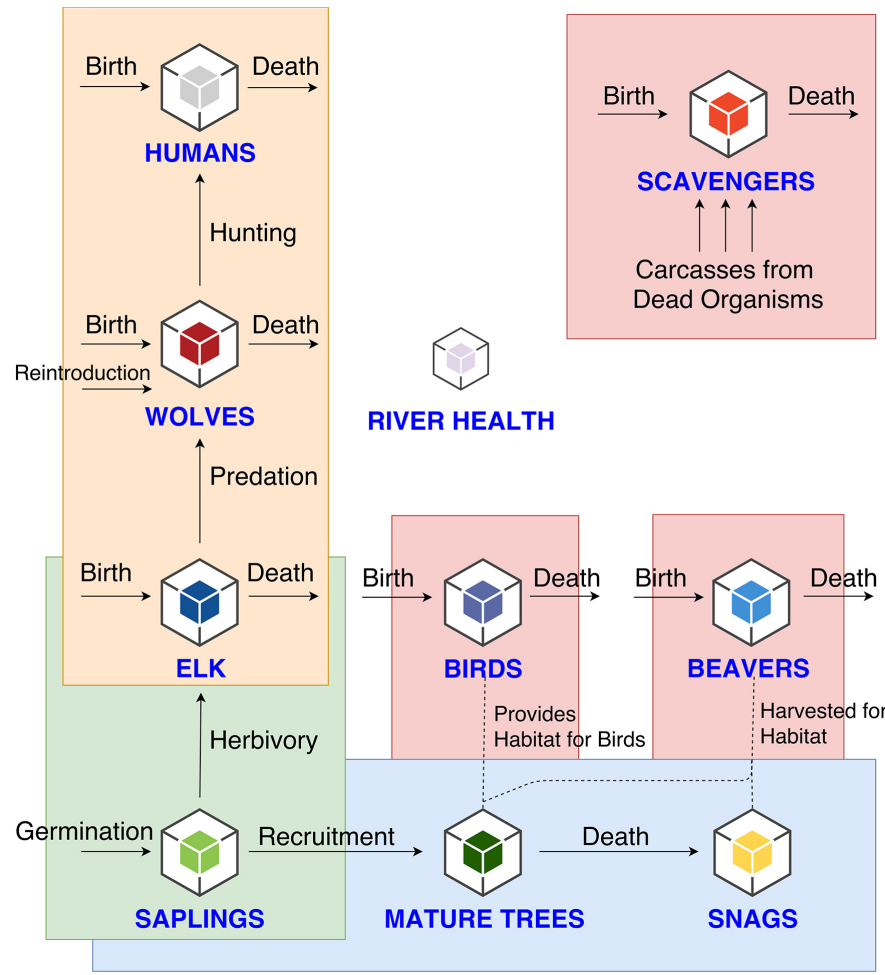

Figure 2. A concept map developed to illustrate the organisms and ecological processes involved in determining river movement and health in Yellowstone National Park.

to classroom-based learning, this research represents one cycle of design-based implementation research (Fishman, Penuel, Allen, Cheng, \& Sabelli, 2013). Situated in a southern state whose standards are based on Next Generation Science Standards, students are required to learn about food webs, species interactions, and the negative impact of human actions (Next Generation Science Standards Lead States, 2013). The standards, however, fail to capture the emergent and 
complex nature of ecosystem dynamics represented in the Yellowstone Problem. To address this failure, a 4-day ecology unit was generated with teacher input. This unitcontained: 1) a teacher lesson plan; 2) student materials; 3) resource packets; and 4) instructions for accessing and using the GbCC Wolf-Sheep Predation model (Wilensky, 1997). The 4-day unit is described in Table 1.

One science teacher who instructs four fifth-grade and four sixth-grade classrooms volunteered to implement the unit after being approached by one of the authors. Upwards of 300 students were able to explore the complex story of how the presence of wolves generates a cascade of effects that influence plant and river patterns in Yellowstone National Park; however, due to incomplete collection, only 112 student material packets were collected. The student body is classified by the state as majority economically disadvantaged (62.8\%), and the ethnic or racial demographics are provided in Table 2.

Table 1. Description of the 4-day unit.

\begin{tabular}{|c|c|c|}
\hline & Lesson & Description \\
\hline 1) & $\begin{array}{l}\text { Introduction to How } \\
\text { Wolves Shape Rivers }\end{array}$ & $\begin{array}{l}\text { Students begin the unit by watching the short video created by } \\
\text { Sustainable Man, which describes the Yellowstone Problem (How } \\
\text { Wolves Change Rivers, 2014) }{ }^{\mathrm{a}} \text {. Students read and analyzegraphics, } \\
\text { visualizations, and other information sources about the agents } \\
\text { involved: wolves, elk, and aspen trees. Students culminate the lesson } \\
\text { by writing a position statement regarding the following prompt: } \\
\text { Should wolves be protected from hunting in Yellowstone? }\end{array}$ \\
\hline 2) & $\begin{array}{l}\text { Introduction to the } \\
\text { Group-based Cloud } \\
\text { Computing (GbCC) } \\
\text { Wolf-Sheep Predation } \\
\text { Model }\end{array}$ & $\begin{array}{l}\text { Students explore the GbCC Wolf-Sheep Predation model in pairs } \\
\text { with Google Chrome books. Students are given the challenge to run } \\
\text { the model with varying amounts of wolves to note the outcomes. } \\
\text { Students end the lesson by thinking about what makes a strong } \\
\text { argument. }\end{array}$ \\
\hline 3) & Generating an Argument & $\begin{array}{l}\text { Students generate a final position and supporting evidence for or } \\
\text { against protecting wolves in Yellowstone. Students use the GbCC } \\
\text { models to generate evidence to support their position. }\end{array}$ \\
\hline & Presentations & $\begin{array}{l}\text { Students present their poster displaying their argument for } \\
\text { protecting wolves in Yellowstone. }\end{array}$ \\
\hline
\end{tabular}

a"How Wolves Change Rivers," 2014, Retrieved from https://sustainablehuman.tv/remix/how-wolves-change-rivers

Table 2. Student ethnicity percentages 2015-2016 reported from the state's department of education website.

\begin{tabular}{cc}
\hline Ethnicity & $\%$ \\
\hline Hispanic or Latino & 15.5 \\
White or European American & 16.8 \\
Black or African American & 66.3 \\
\hline
\end{tabular}

The student body is classified as majority economically disadvantaged (62.8\%). 
Student material packets were collected, digitized, and analyzed. These resources allowed us to evaluate the degree to which GbCC capabilities expand participatory learning. The cooperating teacher offered feedback regarding the logistics and experiences of using GbCC in the classroom. Findings assisted us in understanding how well and under what conditions the GbCC model-based lessons were successful at expanding participation, engaging students in model-based reasoning, and uncovering the complex relationships involved in the Yellowstone tri-trophic cascade (Collins, 1990).

\section{Features of the GbCC Wolves-Sheep Predation Model}

The GbCC Wolves-Sheep Predation model can be altered or even authored multiple ways. A list of ways the student can manipulate the model is presented below, along with a screenshot of the full model (Figure 3). In this model the students can:

- individually manipulate all sliders and toggles, set up the model, and run the model by pressing "go";

- attempt to find values that either cause extinction of the wolves or sheep, cause overgrazing of the grass, or create an equilibrium between all three species;

- share their code to the gallery by pressing the share button, which sends their graph to the classroom gallery space;

- choose a graph from the gallery by pressing the graph button, which imports the slider values from the chosen graph to the user's slider values so the user can run the same model;

- the command center to make changes to the code that runs the model; and open and author the NetLogo code resulting in direct changes to the functioning of the model.

\section{Results and Discussion}

The 4-day unit took place over the course of 2 weeks in the teacher's classrooms. Students were tasked with generating an argument for or against protection of wolves in Yellowstone supported with evidence from their GbCC modeling experience. Specific questions from the student material packet were identified based on their relevance to the research questions, digitized, and analyzed. Teacher feedbacks in the form of typed responses are provided at the end of the section to frame changes made to the model and the activity.

\subsection{Day 2, Question 2}

Following introduction to the Yellowstone problem, the agents involved, and background information on the environment, students began Day 2 by directly engaging with the GbCC Wolf-Sheep Predation model. After learning how to manipulate sliders and toggles, run the model, and read the graphs, students were prompted to answer the following question: 
powered by NetLogo \& GbCC

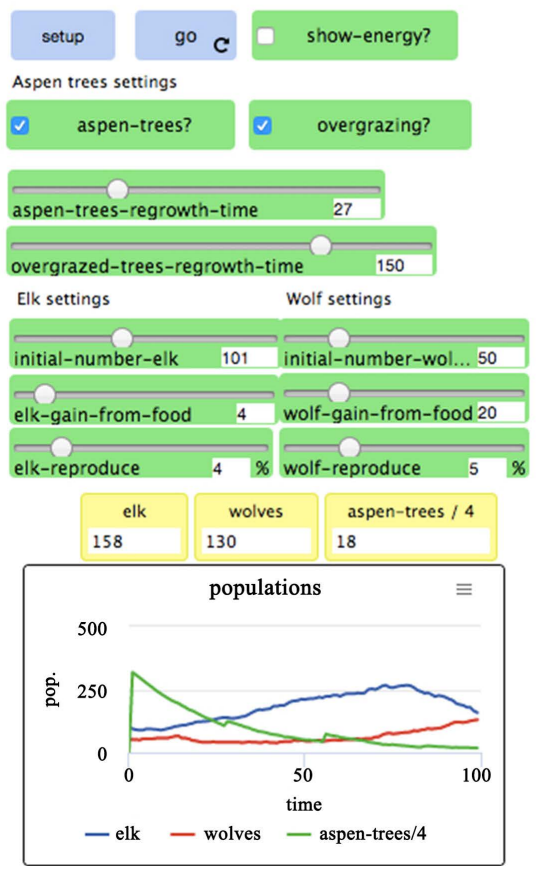

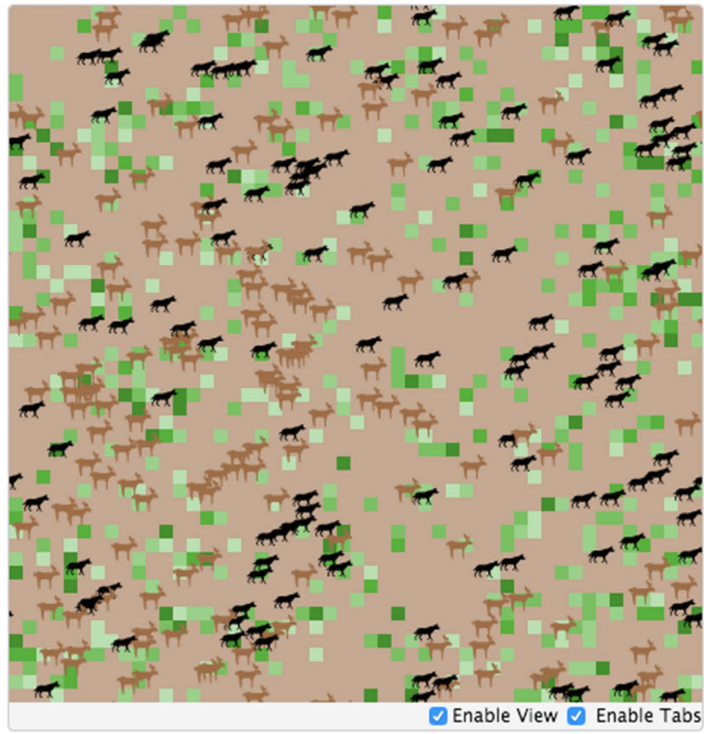

Export: NetLogo World

Figure 3. Group-based cloud computing Wolf-Sheep Predation model with sliders, toggles, visualization, graphs, and netLogo code.

Why would we, as ecologists, use this computer model to learn about wolves, elk, and aspen-and make our argument to the public?

Students worked in pairs to generate answers to this question. Of the 112 student materials packets collected, only 64 contained the page with this question. The teacher mentioned misplacing the work of the other students, which explains the missing data. The list was transcribed, compiled, and read. Schwarz et al. (2009) provided a table of the "candidate components of metamodeling knowledge for a learning progression for modeling" (Table 1, p. 636). The table provided three components of metamodeling knowledge: 1) the nature of models, 2) the purpose of models, and 3) the criteria for evaluating and revising models. Question 2 elicited student ideas about the component of purposes of modeling. Student responses were categorized and examples chosen, as shown in Table 3.

By engaging with the computer model, students were able to easily generate numerous reasons why this tool could support an effective argument. Most frequently, students mentioned the ease of using the computer model due to the long-term and large-scale nature of learning about wolves in Yellowstone. Students also touched upon ideas of using the computer model to determine which amount of wolves would be healthy for the ecosystem, which is evidence of students thinking about models as generative or predictive tools. Going forward, activities designed around using GbCC modeling capabilities should involve more time spent with the models as well as group conversations about the purposes, uses, limitations, and affordances of modeling. 
Table 3. Example student responses for each of the four subthemes within the purposes of modeling component.

\begin{tabular}{|c|c|c|}
\hline Component & Subcomponent & Example student responses \\
\hline \multirow{4}{*}{$\begin{array}{l}\text { Purposes of } \\
\text { modeling }\end{array}$} & $\begin{array}{l}\text { Models are sense-making tools for } \\
\text { constructing knowledge. }\end{array}$ & $\begin{array}{l}\text { "To see the effect" } \\
\text { "Easier to see" } \\
\text { "Our school isn't in Yellowstone park." } \\
\text { "Easier on computers." } \\
\text { "To see how it would work." }\end{array}$ \\
\hline & $\begin{array}{l}\text { Models are communication tools for } \\
\text { conveying understanding or knowledge. }\end{array}$ & $\begin{array}{l}\text { "Because you see the results before doing } \\
\text { it." } \\
\text { "For training." }\end{array}$ \\
\hline & $\begin{array}{l}\text { Models can be used to develop new } \\
\text { understandings, by predicting new aspects } \\
\text { of a phenomenon }\end{array}$ & "Learn which numbers work best." \\
\hline & $\begin{array}{l}\text { Models are used to illustrate, explain, and } \\
\text { predict phenomena. }\end{array}$ & $\begin{array}{l}\text { "It can show us and not hurt the } \\
\text { environment." } \\
\text { "We use simulation because we will know } \\
\text { what [is] going to happen." }\end{array}$ \\
\hline
\end{tabular}

\subsection{Day 2, Questions 3 and 4}

To stimulate students' exploration of the model, two questions were provided that allowed students to see the extremes of the Yellowstone Problem: complete extirpation of wolves and overpopulation of wolves. The question below allowed students to simulate the scenarios and take notes on the outcomes:

What happens when you put no wolves in the mode? What happens when you put a lot of wolves in the mode?

Students overwhelmingly responded to these questions in the manner that the researchers and teacher had hoped. For Question 3, of the 112 responses collected from students, 99 responded with some acknowledgement that removal of wolves would lead to an increased sheep population. Student responses ranged in detail and sophistication. Some mentioned simply that there were more sheep, and some generated a more detailed cause-effect response. For example, one student replied, "The population of sheep increased and there is less grass, then the sheep decreased." This student acknowledged the cyclical nature of sheep (elk) and grass (aspen) populations when left unchecked by the presence of wolves.

Similarly, when students simulated the model with a large number of wolves, the majority of students (95 of 112) responded with some answer related to the declining number of sheep, but relatively few students capture the cyclical nature of populations. One student responded, "The sheep will decrease because the wolves ate them all, and also the wolves will decrease because they ate all the sheep and the wolves will have nothing to eat."

A possible explanation of the breadth of responses yet lack of depth of student answers could be related to the amount of time spent allowing students to explore the models and write. In this 50-minute lesson, students only received 
about 20 minutes of time to explore the model and write about their conclusions. In the future, more time will be allocated for free exploration of the models.

\subsection{Teacher Feedback}

The cooperating teacher provided feedback after the series of lessons about the benefits and challenges of using GbCC in the classroom as well as the nature of participation and engagement. The responses are listed in Table 4.

The most salient feature of GbCC is the ability to share models to the gallery space for other students to use; however, the teacher noted that only the sixth graders used this feature. More research is needed to determine what factors contribute to students sharing their models to the gallery space and using models from the gallery space.

Moving forward, this research allows for the continued exploration of (a) next-generation, fully authorable, collaborative, cloud-based computing focused on science, technology, engineering, and mathematics (STEM) and (b) participatory approaches to modeling and classroom-based inquiry aimed at advancing student abilities in STEM-related coursework and careers. Our research represents one step in the cycle of development and implementation across many schools, subject areas, and grade levels. Findings suggest that teachers and students would prefer more time spent with the simulation as well as tasks that

Table 4. Feedback provided from the cooperating teacher.

\begin{tabular}{|c|c|}
\hline Question & Response \\
\hline $\begin{array}{l}\text { What did you find beneficial } \\
\text { about teaching using } \\
\text { group-based cloud } \\
\text { computing (GbCC), } \\
\text { specifically the wolves and } \\
\text { sheep simulation? }\end{array}$ & $\begin{array}{l}\text { The kids loved it! At the start they understood how serious the loss } \\
\text { of gray wolves was to Yellowstone. They understood even more } \\
\text { when I showed them how the gray wolves population was } \\
\text { extremely important to Yellowstone because it kept Yellowstone in } \\
\text { balance. When they were able to see the simulation of the wolves } \\
\text { and sheep and how the sheep overtook the area and then ate all the } \\
\text { grass, they understood that the need for wolves in order for } \\
\text { Yellowstone to be healthy was every important. }\end{array}$ \\
\hline $\begin{array}{l}\text { What did you find challeng- } \\
\text { ing? }\end{array}$ & $\begin{array}{l}\text { Mostly that the site kept crashing. Some of the buttons and } \\
\text { numbers seemed confusing to the kids, and they didn't know what } \\
\text { to do with them. Most of the lesson were too fun to find } \\
\text { challenging. For fifth grade, though, I hyped it up and made it my } \\
\text { own because the lesson wasn't as "kid friendly" as I hoped it would } \\
\text { be. Getting to discover different species of wolves is something } \\
\text { added to make it more fun. }\end{array}$ \\
\hline $\begin{array}{l}\text { Did your students use the } \\
\text { Gallery feature of the } \\
\text { simulation? }\end{array}$ & $\begin{array}{l}\text { My fifth graders didn't, but my sixth graders did. They shared with } \\
\text { each other how to keep the area balanced and what process they } \\
\text { used to do that. }\end{array}$ \\
\hline $\begin{array}{l}\text { How was participation in } \\
\text { your class when using the } \\
\text { GbCC Wolves-Sheep } \\
\text { Predation model? }\end{array}$ & $\begin{array}{l}100 \% \text { participation. They loved getting on the computer and being } \\
\text { able to push buttons and see what happened. Sixth grade liked the } \\
\text { gallery feature a lot and shared with people outside of their groups. }\end{array}$ \\
\hline
\end{tabular}


facilitate students' use of the gallery share and authoring features. This scalable and low-cost technological and pedagogical infrastructure is intended to directly increase student and teacher involvement with high-quality STEM learning experiences.

\section{Acknowledgements}

The authors would like to thank the students and teachers who participated in this study. This material is based upon work supported by the National Science Foundation under Grant No. DRL-1615207. The opinions expressed here are those of the authors above.

\section{References}

Collins, A. (1990). Toward a Design Science of Education. Technical Report No. 1. New York, NY: Center for Technology in Education.

Fishman, B. J., Penuel, W. R., Allen, A.-R., Cheng, B. H., \& Sabelli, N. (2013). Design-Based Implementation Research: An Emerging Model for Transforming the Relationship of Research and Practice. Yearbook of the National Society for the Study of Education, 112, 136-156.

How Wolves Change Rivers (2014). https://sustainablehuman.tv/remix/how-wolves-change-rivers

Next Generation Science Standards Lead States (2013). Next Generation Science Standards: For States, by States. Washington DC: The National Academies Press.

Petrosino, A. J., \& Stroup, W. M. (2017). Group-Based Cloud Computing for STEM Education. Columbus: Poster at the Annual Convention of the American Society of Engineering Education.

https://www.asee.org/public/conferences/78/papers/19018/view

Philip, T., \& Garcia, A. (2013). The Importance of Still Teaching the iGeneration: New Technologies and the Centrality of Pedagogy. Harvard Educational Review, 83, 300-319. https://doi.org/10.17763/haer.83.2.w221368g1554u158

Ripple, W. J., \& Beschata, R. L. (2012). Trophic Cascades in Yellowstone: The First 15 Years after Wolf Reintroduction. Biological Conservation, 145, 205-213.

https://doi.org/10.1016/j.biocon.2011.11.005

Schwarz, C. V., Reiser, B. J., Davis, E. A., Kenyon, L., Achér, A., Fortus, D., Krajcik, J. et al. (2009). Developing a Learning Progression for Scientific Modeling: Making Scientific Modeling Accessible and Meaningful for Learners. Journal of Research in Science Teaching, 46, 632-654. https://doi.org/10.1002/tea.20311

Stroup, W. M., Ares, N., \& Hurford, A. C. (2004). A Taxonomy of Generative Activity Design Supported by Next-Generation Classroom Networks. Proceedings of the 28th Annual Conference of Psychology in Mathematics Education-North America, Ontario, 837-846.

Stroup, W. M., Ares, N., Lesh, R., \& Hurford, A. (2007). Diversity by Design: Generativity in Next-Generation Classroom Networks. In R. Lesh, E. Hamilton, \& J. J. Kaput (Eds.), Models and Modeling as Foundations for the Future in Mathematics Education (pp. 367-393). Mahwah, NJ: Erlbaum.

Wells, G. (1993). Reevaluating the IRF Sequence: A Proposal for the Articulation of Theories of Activity and Discourse for the Analysis of Teaching and Learning in the Classroom. Linguistics and Education, 5, 1-37. 
https://doi.org/10.1016/S0898-5898(05)80001-4

Wilensky, U. (1997). NetLogo Wolf Sheep Predation Model. Evanston, IL: Northwestern University, Center for Connected Learning and Computer-Based Modeling. http://ccl.northwestern.edu/netlogo/models/WolfSheepPredation

Wilensky, U., \& Reisman, K. (2006). Thinking Like a Wolf, a Sheep, or a Firefly: Learning Biology through Constructing and Testing Computational Theories-An Embodied Modeling Approach. Cognition and Instruction, 24, 171-209. https://doi.org/10.1207/s1532690xci2402_1

Wilensky, U., \& Stroup, W. (2002). Computer-HubNet. Evanston, IL: Northwestern University. http://ccl.northwestern.edu/netlogo/hubnet.html

Wittrock, M. C. (1991). Generative Teaching of Comprehension. The Elementary School Journal, 92, 169-184. https://doi.org/10.1086/461686 